$$
\text { الأمر اض الفيروسية على التفاح في جنوب سورية }
$$

\title{
Viral diseases on apple in southern Syria
}

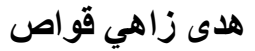 \\ قسم وقاية النبات/ كلية الزر اعة / جامعة دمثق
}

Houda Z. Kawas

Plant Protection Department/ Faculty of Agriculture/ Damascus University

المستخلصن

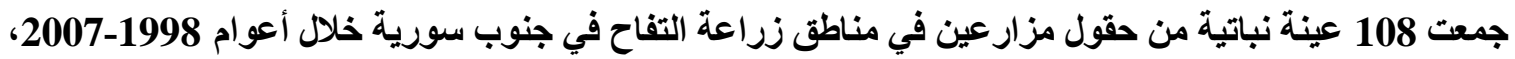

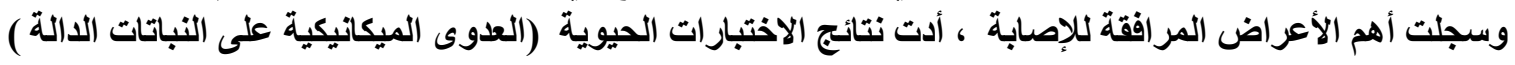

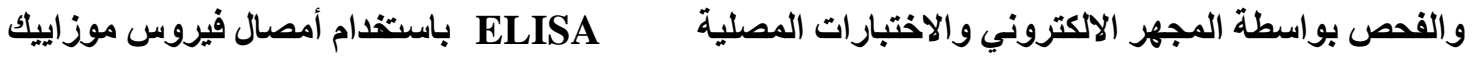
Apple chlorotic leaf spot virus وفيروس التبقع الثاحب لأوراق التفاح Apple mosaic virus وفيروس التبقع الحلقي للبندورة Tomato ring spot virus وفيروس الذبول المتبقع للبندورة Tomato sobotted wilt virus وفيروس التبقع الحلقي للتبغ Tobacco ring spot virus وفيروس الحلقة السوداء للبندورة Tomato black ring virus وفيروس موزاييك الأرابيس Arabis mosaic virus إلى انتثار

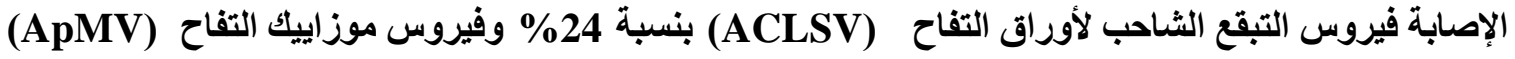

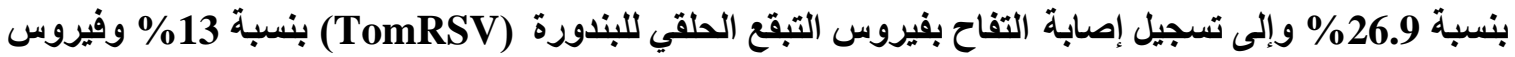

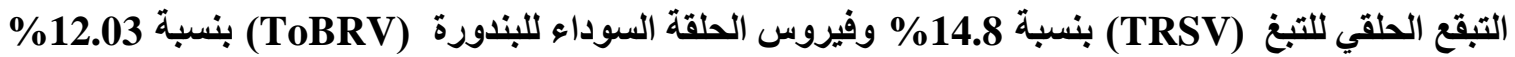

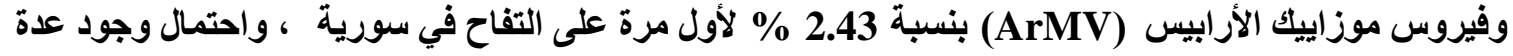

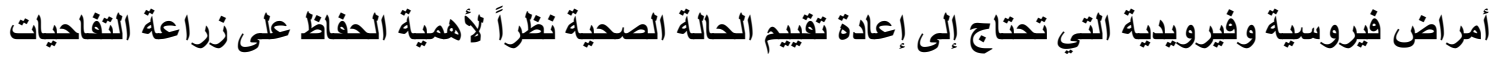

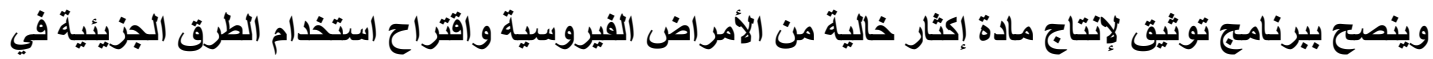

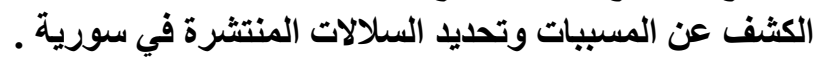

Abstract

108 sample Collected from the fields of farmers in the areas of apple cultivation in the south of Syria during the years 1998-2007, and the most important symptoms associated with infection were recorded, results of the biometric tests (mechanical inoculation on indicator plant) and examination by electron microscope and serological tests (ELISA) using antisera of Apple mosaic virus, Apple chlorotic leaf spot virus, Tomato ring spot virus, Tomato spotted wilt virus, Tobacco ring spot virus, Tomato black ring virus and Arabis mosaic virus to the spread of a virus infection of Apple chlorotic leaf spot virus (ACLSV) by 24\%, Apple mosaic virus (ApMV) by $26.9 \%$ and to register cases Tomato ring spot virus (TomRSV) by $13 \%$ and Tobacco ring spot virus (TRSV) by \%14.8, Tomato black ring virus (TBRV) rate of \% 12.03 and Arabis mosaic virus (ArMV) $2.43 \%$ for the first time on apples in Syria, and the likelihood of several viral and viroid diseases, that we need to reassess the health situation in view of the importance of maintaining the cultivation of apples and recommended program documentation for the production of propagation of disease-free, with proposal to use molecular methods to detect and identify viral diseases causes and strains prevalent in Syria.

كلمات مفتاحية: تفاح ، فيروسات ، اليزا ، نباتات دالة ، جنوب سوريةة .

Keywords: apple, viruses, ELISA, Indicator plants, southern Syria. 
تصاب أشجار التفاحيات (التفاح .Malus communis L. السفرجل .Cydonia oblonga Mill، و الأجاص

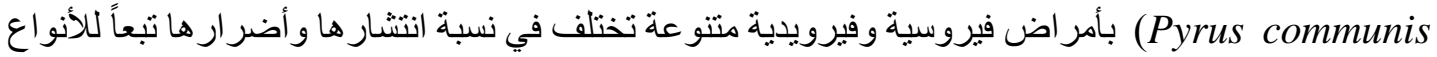
والأصناف المزروعة وباختلاف مناطق زر اعتها في العالم ، كما تختلف بآليات انتقالها وسلالات الفيروس وتحمل الأصناف ، بلغت المساحة المزرو عة بالتفاح حو الي 50 ألف هكتار أنتجت نحو 400 ألف ألف طن في عام 2007 في في

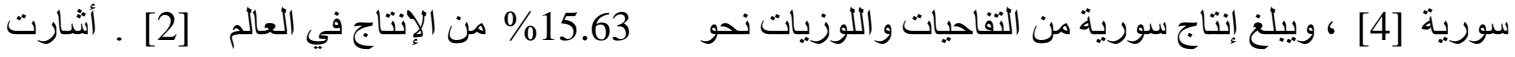

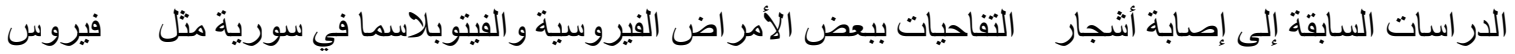

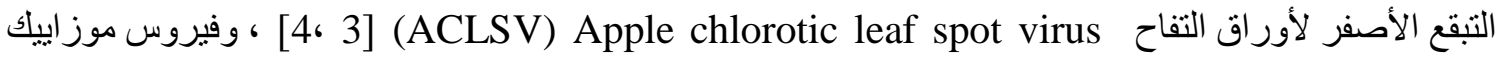

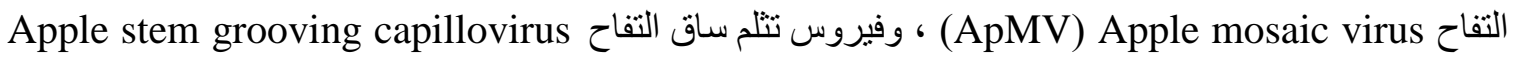

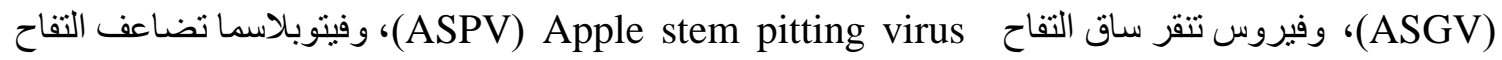
6andidatus phytoplasma mali

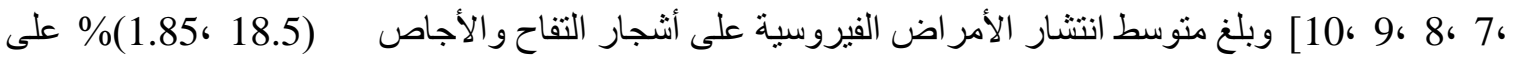

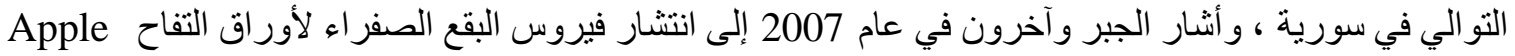
و ولغ منوسط نسبة الإصابة بهذا الفيروس في عينات التفاحيات 21.9 وسجلت أعلى نسبة إصابة على التفاح 42.5\% وكانت نسبة الإصابة بكل من فيروس تثلم ساق التفاح

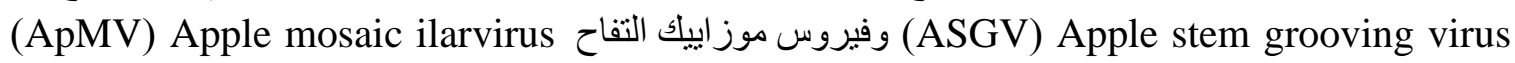

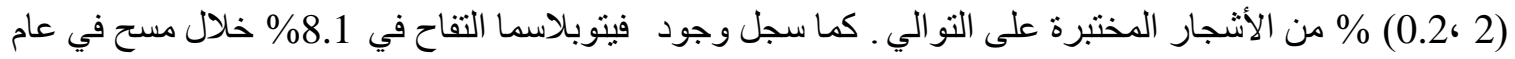

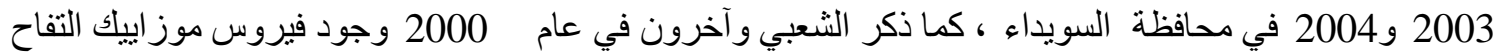

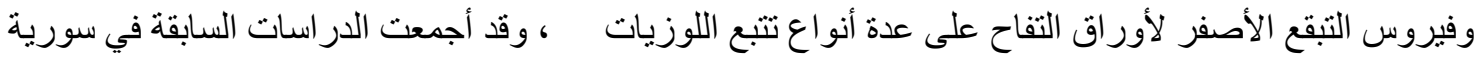

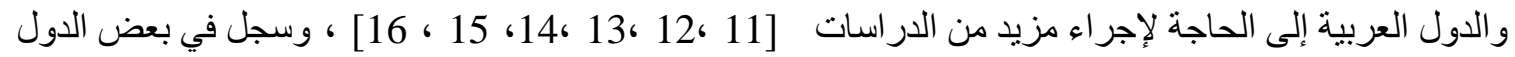
العربية مثل جمهورية مصر العربية والأردن وجود فيروس التبقع الحلقي للبندورة Tomato ringspot virus و Xiphinema americanum Cobb. على أثجار اللوزيات وينتقل هذا الفيروس بواسطة نيماتودا (TomRSV) X. brevicolle Lord. Et Da ، X. californicum Lam. et Bleve-Zacheo. ، X. riversi Dalmasso Costa ، والمعروف في قدرته على إحداث ظاهرة عدم تو افق الطعم مع الأصل وفي تماوت منطقة التطعيم كما في ،

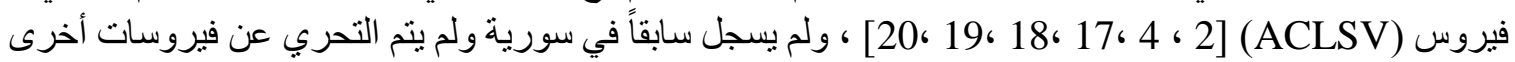

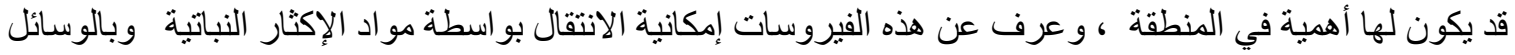
الطبيعية (كغبار الطلع أو البذور أو بواسطة حشر ات المن أو النطاطات أو النيماتودا) ) وينتشر الفيروسين ACLSV

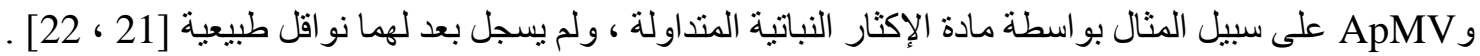

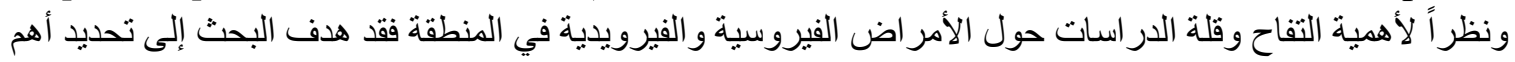

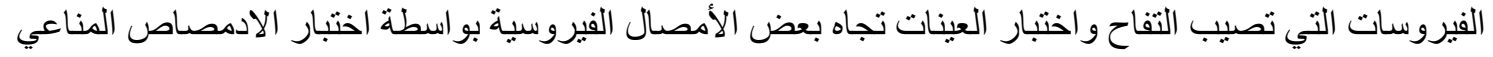
المرتبط بالإنزيم ELISA ودر اسة الانتقال الميكانيكي على النباتات الدالة والفحص بو اسطة المجهر الالكتروني لأهم العينات .

\section{مواد وطرائق البحث}

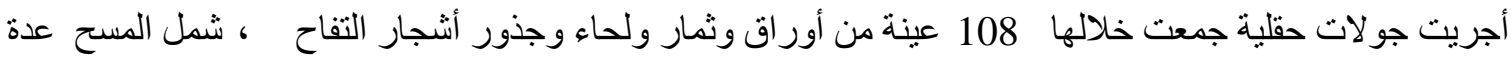

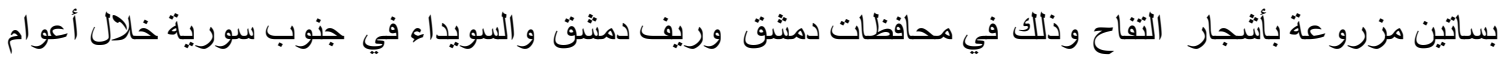

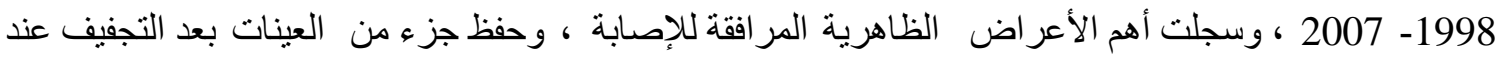

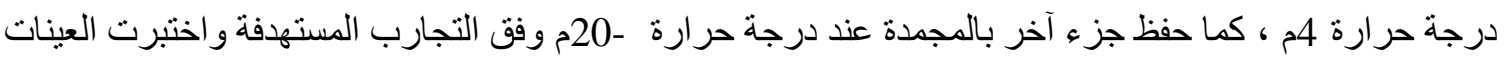




\section{الاختبارات المصلية}

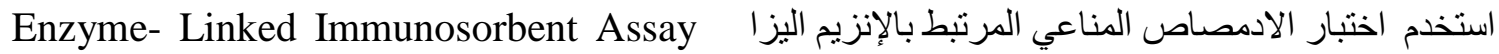
وفق الطريقة الموصوفة سابقاً [23] للكثف عن الفيروسات ، استخدمت أمصال مضادة متعددة الكلون (ELISA)

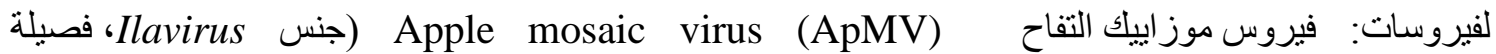
Apple chlorotic leaf spot virus (ACLSV) وفيروس التبقع الثاحب لأور اق التفاح) (Aromoviridae

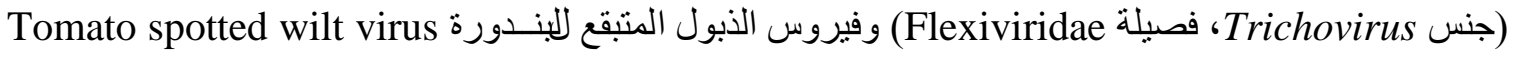

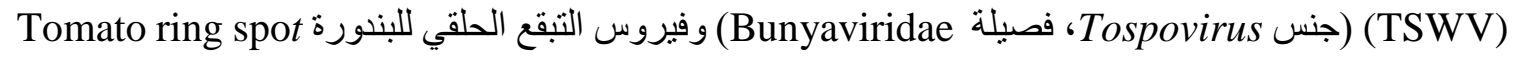

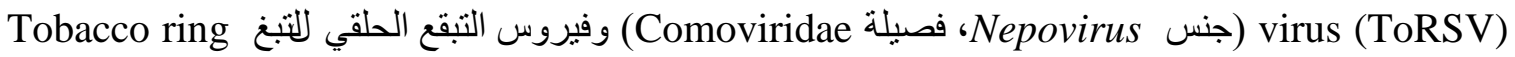

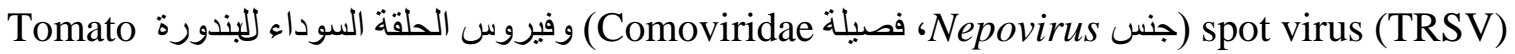

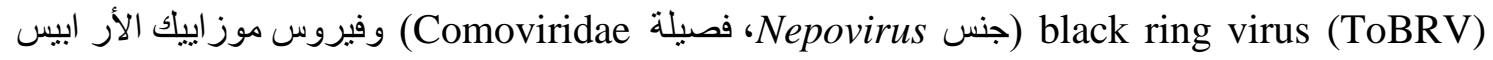

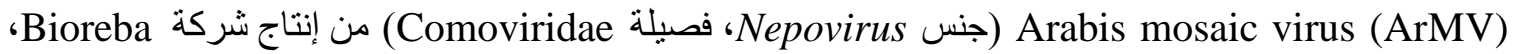

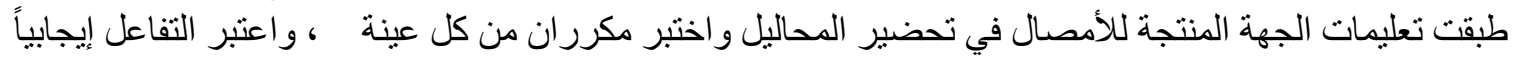

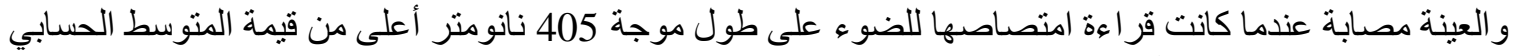

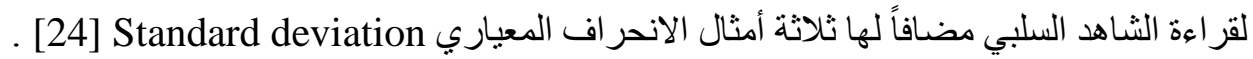

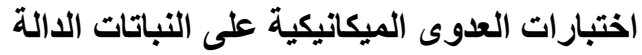

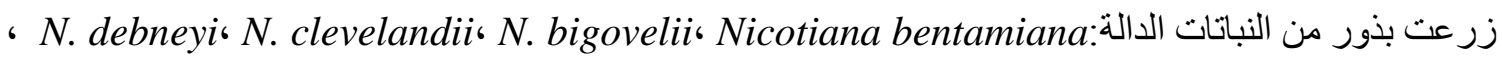
، N. tabacum sumson، N. sylvestris‘ N. rustica $N$. occidentalis $N$. hesperis‘ $N$. glotinosa Ch. ' Ch. murale ‘ Chenopodium album ‘ Brassica pekinensis ${ }^{N}$. tabacum white burley D. ' Datura metel، Cucurbita pepo' Cucumis sativus' Ch. quinoa‘amaranticolor Petunia ، Lycopersicon esculentum ، Lactuca sativa Gomphrena globosa، stramonium Vigna ‘Vicia faba، Pisum sativum، Physalis floridana، Phaseolus vulgaris، hybrid

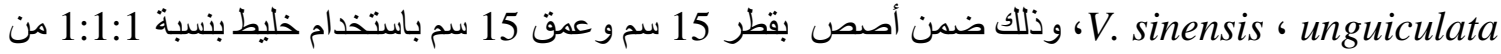

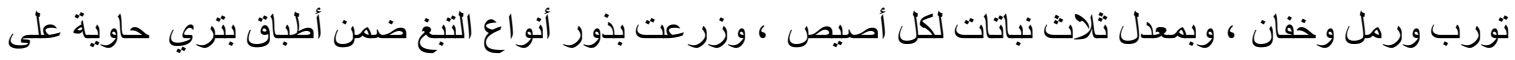

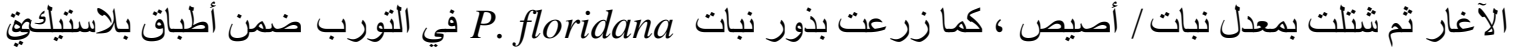
ثم شتلت بمعدل نبات/أصيص ، و واستخدمت في تجارب العدوى الميكانيكية والانتقال الحيوي وفي حفظ السلالات

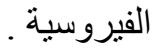

العزلات الفيروسية المستخدمة : اختيرت عزلات تختلف فيما بينها بأعر اض الإصابة الظاهرة على أوراق التفاح

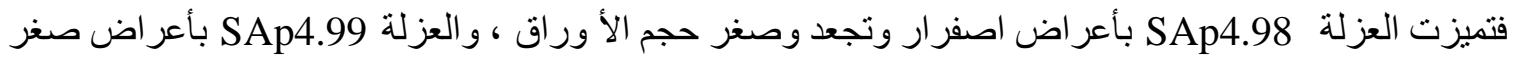

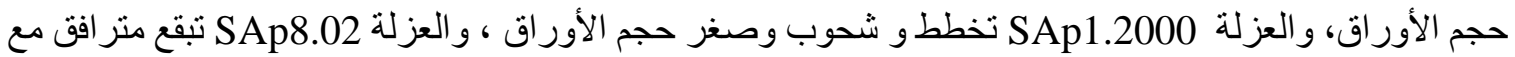

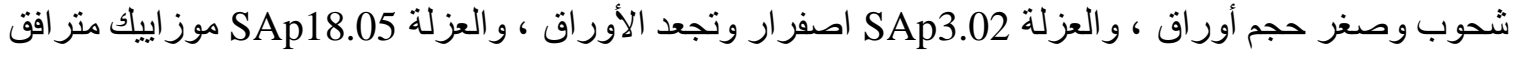

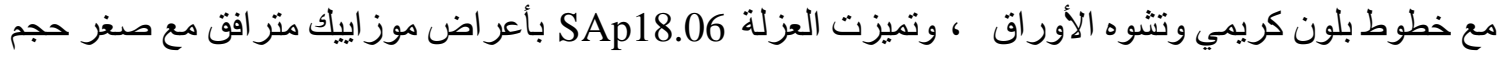

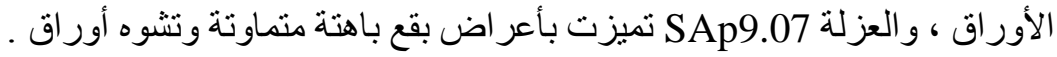

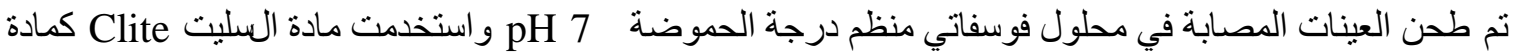

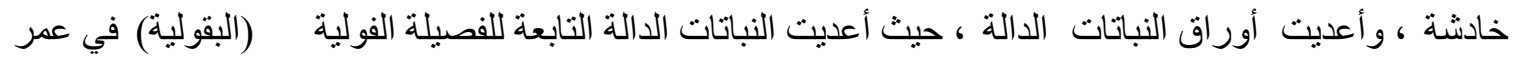

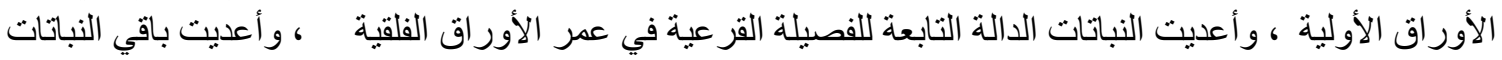

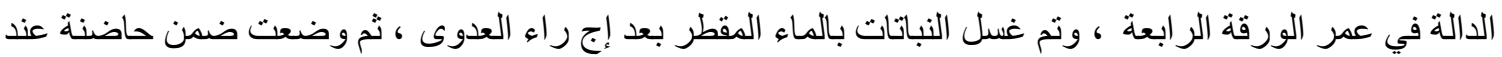

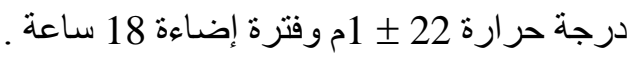




\section{الفحص بواسطة المجهر الأكتروني}

Transmission Electron Microscope تم فحص 4 عينات من عينات أوراق تفاح بواسطة المجهر الالكتروني

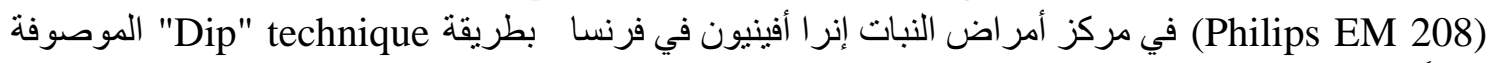

أدى اختبار 108 عينات التفاح من جنوب سورية بواسطة اختبار ELISA إلى التفاعل الإيجابي مع كافة الأمصال

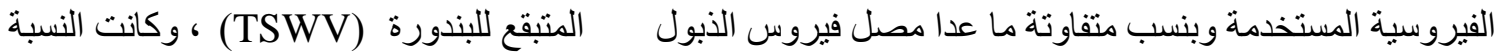

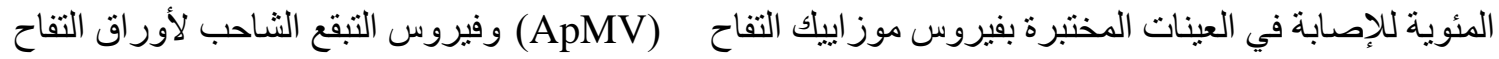

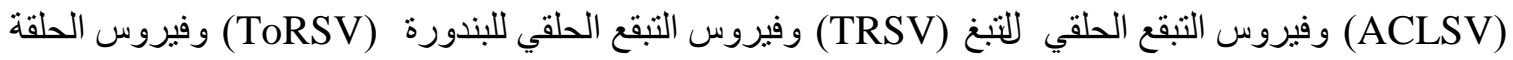

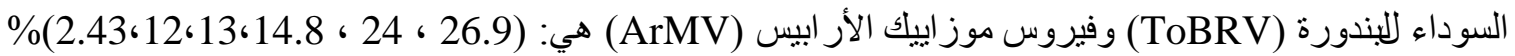

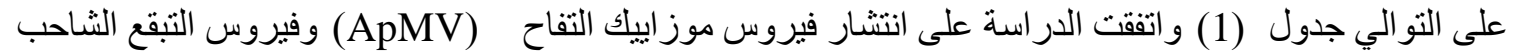

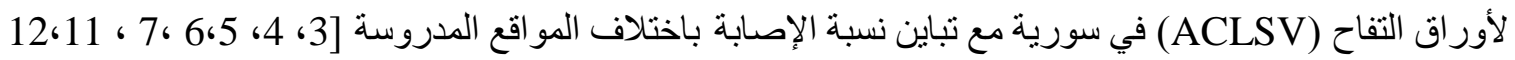

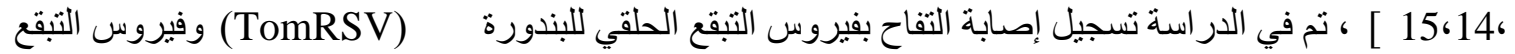
الحلقي للتبغ (TRSV) وفيروس الحلقة السوداء للبندورة (ToBRV) وفيروس موز اييك الأرابيس (ArMV) لأول

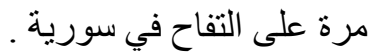
و أدى فحص عينات التفاح بوا سطة المجهر الإلكتروني إلى وجود جسيمات فيروسية كروية متناظرة النكل يتراوح

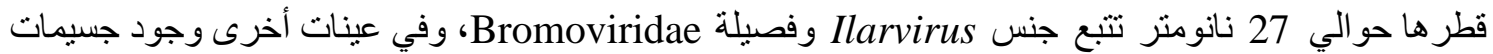

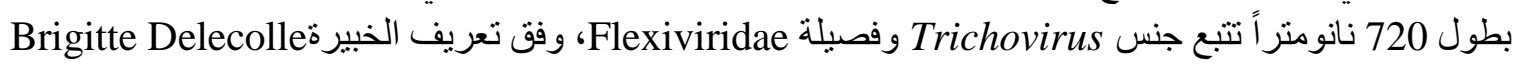
في مخبر إنرا أفينيون ونو افقت نتائج الفحص بو استولة المجهر الإلكتروني مع تجارب العدوى الميكانيكية والاختبار

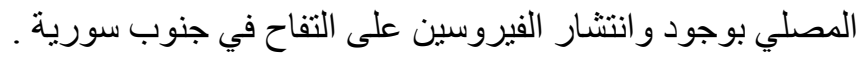

جدول (1): أنواع الفيروسات وعدد العينات ايجابية التفاعل بواسطة اختبار ELISA ونسبة الإصابة في عينات التفاح من جنوب سورية

\begin{tabular}{|c|c|c|c|}
\hline النسبة المئوية & عداد العينات إيجابية & عدد العينات & 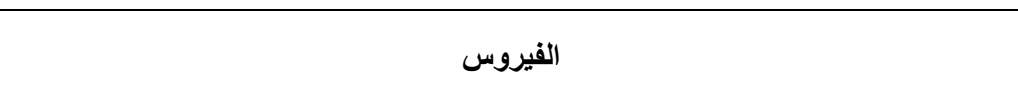 \\
\hline 26.9 & 29 & 108 & (ApMV) Apple mosaic virus \\
\hline - & - & 108 & فيروس الذبول المتبقع للبنـدورة TSWV) Tomato spotted wilt virus) \\
\hline 13 & 14 & 108 & فيروس التبقع الحلقي للبندورة (ToRSV) Tomato ring spot virus \\
\hline 14.8 & 16 & 108 & فيروس التبقع الحلقي للتبغ (TRSV) Tobacco ring spot virus \\
\hline 12 & 13 & 108 & فيروس الحلقة السوداء للبندورة ToBRV) Tomato black ring virus) \\
\hline 2.43 & 2 & 82 & فيروس موزاييك الأرابيس ArMV) Arabis mosaic virus \\
\hline 24 & 26 & 108 & فيروس التبقع الثناحب لأوراق التفاح ACLSV) Apple chlorotic leaf spot virus) \\
\hline
\end{tabular}

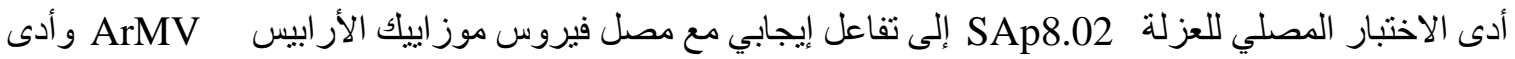

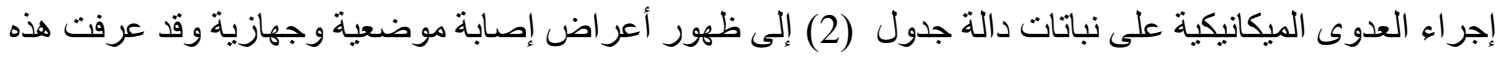

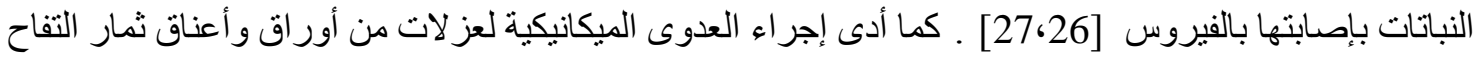

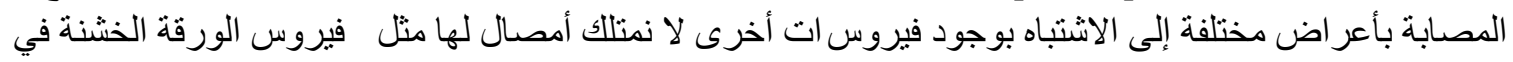

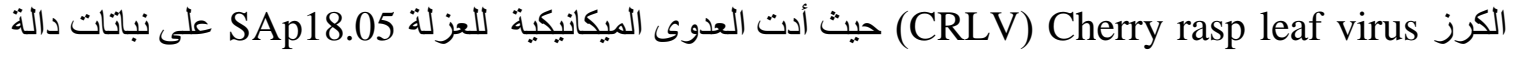
، Physalis floridana ، Cucumis sativus ، C.amaranticolor ، Chenopodium quinoa

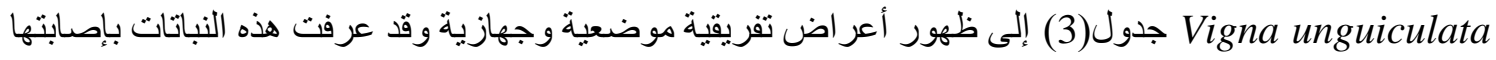

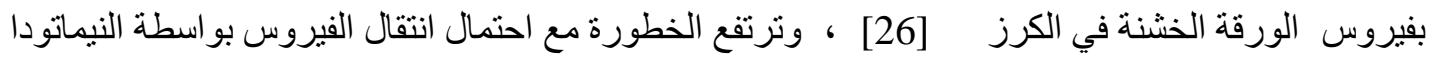
. [26] (Dorylamidae) Xiphinema americana 
جدول (2): أعراض الإصابة الموضعية والجهازية على النباتات الادالة للعزلة SAp8.02 من التفاح المصابة بفيروس موزاييك الأرابيس إيجابية التفاعل بواسطة ELISA من جنوب سورية الإصاتش

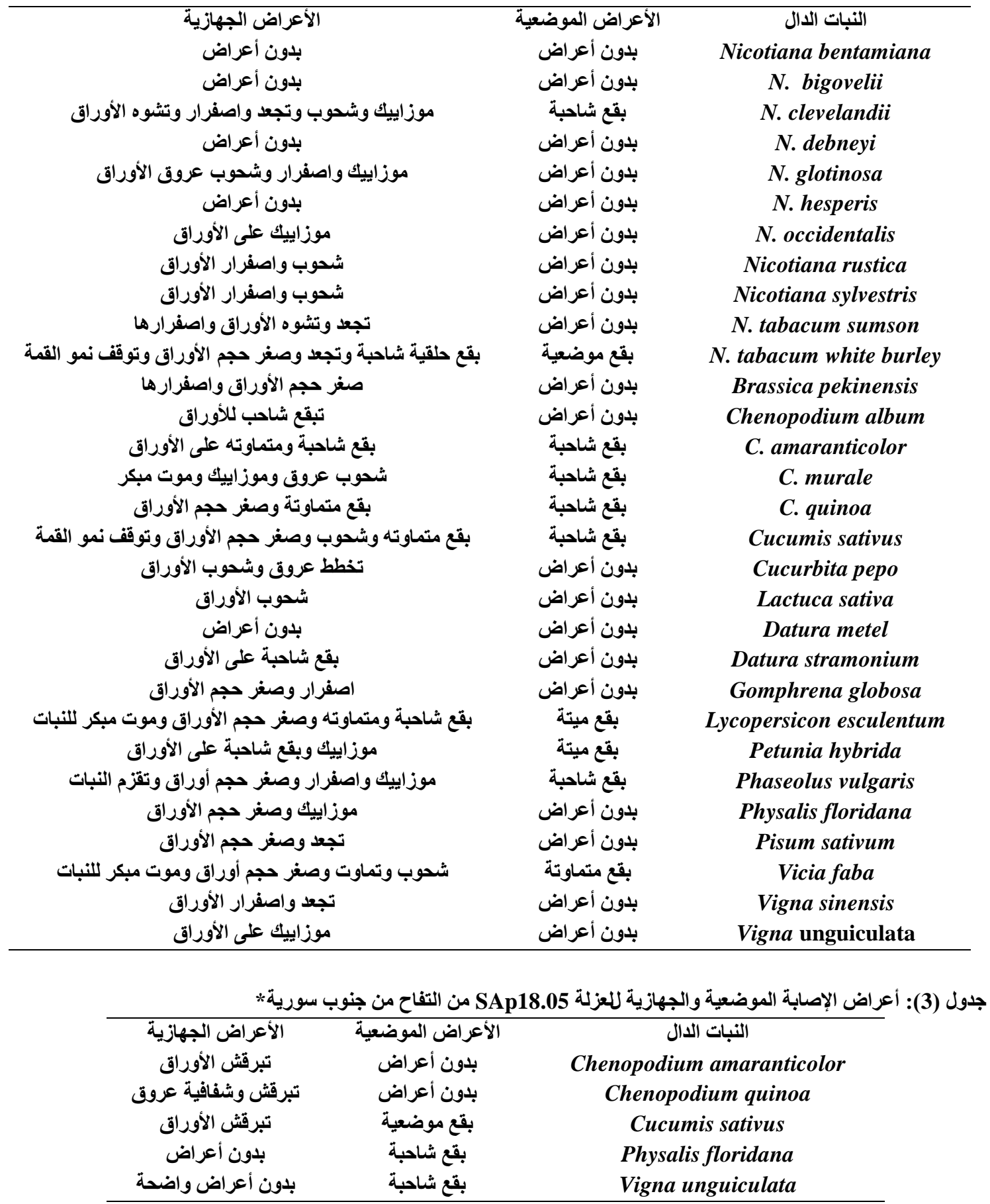

*أنواع النباتات الدالة الواردة في جدول .2 ولم تذكر في الجدول لم تبد أي أعراض ظاهرة نتيجة العدوى الميكانيكية عند اختبار العزلة .SAp18.05 


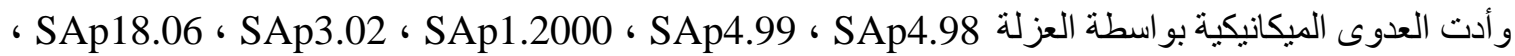

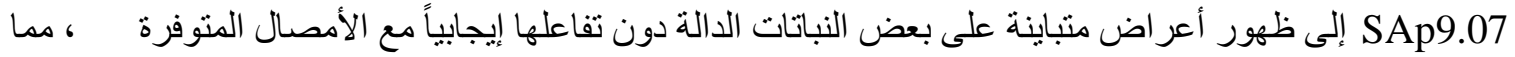

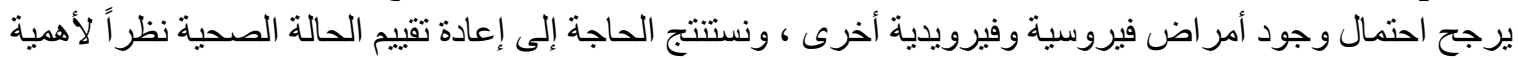

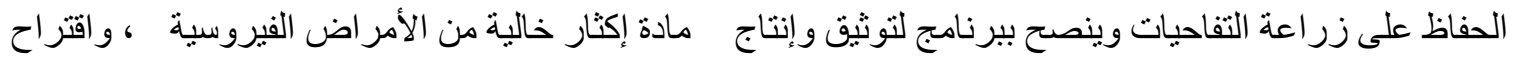

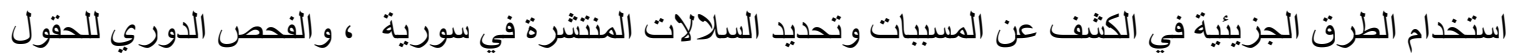
و إز الة الأشجار المصابة أو المحاصيل المر افقة ومكافحة الأعثاب الحولية والمعمرة كمصدر للنو اقل الحيوية

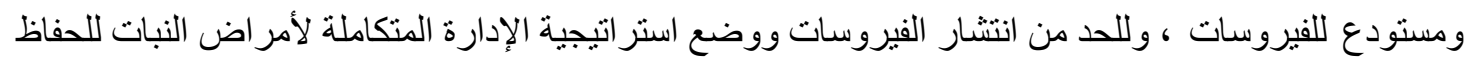

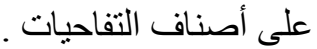

المصادر

1. FAO.2008. FAO satat. Site.

2. مكوك ، خالد محي الدين ، جابر إبر اهيم فجلة وصفاء غسان قمري . 2008 ـ الأمر اض الفيروسية للمحاصيل

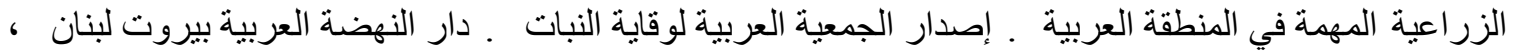

631

3. Dunez, J. 1988. Situation of virus and virus-like diseases of stone fruit in the Mediterranean and Near east region. In: Fruit crop sanitation in the Mediterranean and Near East Region: status and requirements. UNDP/FAO Publication: 226-275.

4. Dunez, J. 1989. Situation of virus and virus-like diseases of stone fruit trees in the Mediterranean and Near east countries. Arab J. Plant Protection, 7 (2): 201-209.

5. Ismaeil, F.; K. Al-Jabor; A. Myrta; M. J. Mando; E. Al-Saadoun; M. Hassan and S. AlChaabi. 2006. Viruses of pome fruit trees in Syria. EPPO Bulletin, 36: 65 - 68.

6. Ismaeil, F.; A. Myrta; N. Abou Ghanem-Sabanadzovic; S. Al Chaabi; A. Chik Darwich and V. Savino. 2003a. Viruses of stone fruit trees in Syria. In: Options méditerranéennes - Série B, No: 45. Virus and virus-like diseases of stone fruits with particular reference to the Mediterranean region, 37-38.

7. Ismaeil, F.; S. Al-Chaabi; A. Myrta and V. Savino. 2003b. Detection and distribution of virus and virus-like diseases of stone fruits in Syria. Arab J. Plant Protection, 21 (2): 73-78.

8. Fulton, R. W. 1972. Apple mosaic virus. C.M.I./A.A.B. Description of Plant Viruses, 83p.

9. Fulton, R. W. 1981. I .laviruses. In: Handbook Of Plant Virus Infections and Comparative Diagnosis (Kurstak, E. (Eds.), Elsevier: 337-413.

10. Myrta, A.; B. Di Terlizzi; V. Savino and G. P. Martelli. 2002. Sanitary status of the mediterranean stone fruit industry, Acta Horticulturae: 1-12.

11. اسماعيل ، فايز، صلاح الثعبي ـ 2007 ـ فيروسات أثنجار التفاحيات في سورية ـ مجلة وقاية النبات العربية .25:63 12. الجبر، خلدون ، عماد اسماعيل وصلاح الثعبي ـ 2007 ـ التحري عن فيروس البقع الورقية الثاحبة على التفاح

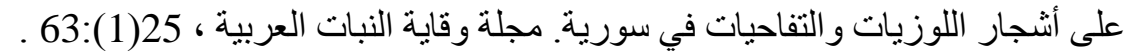
13. تقي الدين ، هلا وخالد مكوك ـ 1986. تحديد بعض الفيروسات التي تصبيب أشجار اللوزيات في لبنان ـ مجلة وقاية

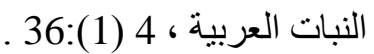

14. Al-Jabr, K.; I. Ismail and S. Al-Chaabi. 2008. A survey for Apple chlorotic leaf spot virus on stone and pome fruits in Syria. Arab J. Pl. Prot., 26: 27-31. 
15. Al-Jabr, A., F. Ismaeil, M. J. Mando, E. Al-Saadoun and S. Al-Chaabi. 2005. First record of pome fruit viruses in Syria. Journal of Plant Pathology, 87 (3): 243.

16. Choueiri, E., N. Abou Ghanem-Sabanadzovic, S. El Zammar and F. Jreijiri. 2003. Viruses of stone fruit trees in Lebanon. In: Options Méditerranéennes Number 45, Virus and virus-like diseases of stone fruits, with particular reference to the Mediterranean region (eds Myrta A, Di Terlizzi B, and Savino V), pp. 25-27. CIHEAM, Valenzano (IT). 17. منصور، عقل ـ 1999 ـ الوضع الر اهن للأمر اض الفيروسية على أشجار اللوزيات /الحلويات في الأردن ـمجلة

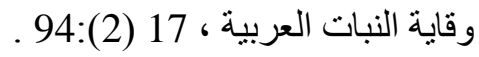

18. Jones, A.L.; and H.S. Aldawinckle. 1990. Compendium of Apple and Pear Diseases. The American Phytopathological Society. St. Paul. Minnesota.USA. Pp.100.

19. Jones, A.L. and T.B. Sutton. 1984. Diseases of tree fruits. Michigan State Univ. North Center Region Extension Publication No.(45) 59pp.

20. Myrta, A.; B. Di Terlizzi; V. Savino and G. P. Martelli. 2003. Virus diseases affecting the Mediterranean stone fruit industry: A decade of surveys. . In: Options Méditerranéennes Number 45, Virus and virus-like diseases of stone fruits, with particular reference to the Mediterranean region (eds Myrta A, Di Terlizzi B, and Savino V), pp. 15-23. CIHEAM, Valenzano (IT).

21. Diekmann, M. And C. A. J. Putter. 1996. Stone fruits. FAO/IPGRI Technical guidelines for the safe movement of germplasm. No. 16, 109 Pp.

22. Delbos, R. and J. Dunez. 1988. Apple chlorotic leaf spot virus. Pages 5-7, in: European Handbook on plant diseases. Eds. Smith,Dunez,Lelliot,Philips and Archer.Blackwell Scientific Publications Ltd,London.

23. Clark, M.F. and A.N. Adams .1977. Characteristics of the microplate method of enzymelinked immunosorbent assay for the detection of plant viruses. Journal of General Virology, 34(3):475-483.

24. Savigny, D.de; and A. Voller. 1980. The communication of ELISA data from laboratory to clinician. Journal of Immunoassay, 1: 105-128.

25. Delecolle, B. 1999. Transmission Electron Microscope "Dip" technique. Station de Pathologic Vegetate. INRA. Domaine St Maurice B.P. 94, 84140 Montfavet. INRA d'Avignon, France.

26. Brunt, A.; K. Crabtree; M. Dallwitz; A. Gibbs,; L. Watson and E. Zurcher. 1996. Plant Viruses Online: Descriptions and Lists from the VIDE Database.

27. Büchen-Osmond, C. (Ed.) 2006. ICTVdB Management: Arabis mosaic virus. In: ICTVdB - The Universal Virus Database, version 4., Columbia University, New York, USA. 